\title{
Mathematical Modeling of Twin -T Notch Filter using Floating Admittance Matrix
}

\author{
Sanjay Kumar Roy ${ }^{1}$, \\ $\mathrm{PhD}$. Scholar at Lovely \\ Professional University and \\ Head (Power Distribution), \\ OMQ Division, TATA Steel \\ Ltd, India \\ corresponding author: \\ sanjay.roy@tatasteel.com
}

\author{
Kamal Kumar Sharma, \\ Professor, Electronics and \\ Communication, Lovely \\ Professional University, \\ Phagwara, Punjab, India
}

\author{
Brahmadeo Prasad Singh, \\ Professor Adjunct, \\ Electronics and \\ Communication, Netaji \\ Subhas University of \\ Technology, New Delhi, \\ India
}

Received: May 21, 2021. Revised: November 10, 2021. Accepted: January 4, 2022. Published: January 5, 2022.

\begin{abstract}
A novel article presents the RC-notch filter function using the floating admittance matrix approach. The main advantages of the approach underlined the easy implementation and effective computation. The proposed floating admittance matrix (FAM) method is unique, and the same can be used for all types of electronic circuits. This method takes advantage of the partitioning technique for a large network. The sum property of all the elements of any row or any column equal to zero provides the assurance to proceed further for analysis or re-observe the very first equation at the first instant itself. This saves time and energy. The FAM method presented here is so simple that anybody with slight knowledge of electronics but understating the matrix maneuvering can analyze any circuit to derive all types of transfer functions. The mathematical modelling using the FAM method allows the designer to adjust their design at any stage of analysis comfortably. These statements provide compelling reasons for the adoption of the proposed process and demonstrate its benefits.
\end{abstract}

Keywords: Notch filter, Floating Admittance Matrix (FAM), Twin-T Network.

\section{INTRODUCTION}

The development of technology at an incredible pace over decades forced the society to employ electronics at an unimaginable proportion of human activities. This necessity induces a constant improvement in the existing and further development of new electronic equipment. Electronic networks such as bridge-T, twin- $\mathrm{T}$, lattice equalizer, and general purposes filter circuits [1]-[6] find a wide application in communication systems.

The parallel combination of an RC low-pass and an RC high-pass forms a ban-pass filter. The bandpass filter passes a band of frequencies of either side of the low-pass or high-pass filter. Combining the same low-pass and high-pass filter can reject a band of frequencies. This type of filter should completely block a band of frequencies or drastically reject the band of frequencies. A unique subset of the bandreject filter is the notch-filter, which rejects extremely low-band of frequencies as in Fig. 1 [7], [8]. A twin-T network forms the parallel combination of two-T complementary RC structures. The twin- $\mathrm{T}$ network is used as a notch filter for rejecting (offering the highest attenuation) the signal at only one frequency, called the notch frequency $\left(f_{o}\right)$ and passes all frequencies on both sides of the notch frequency.

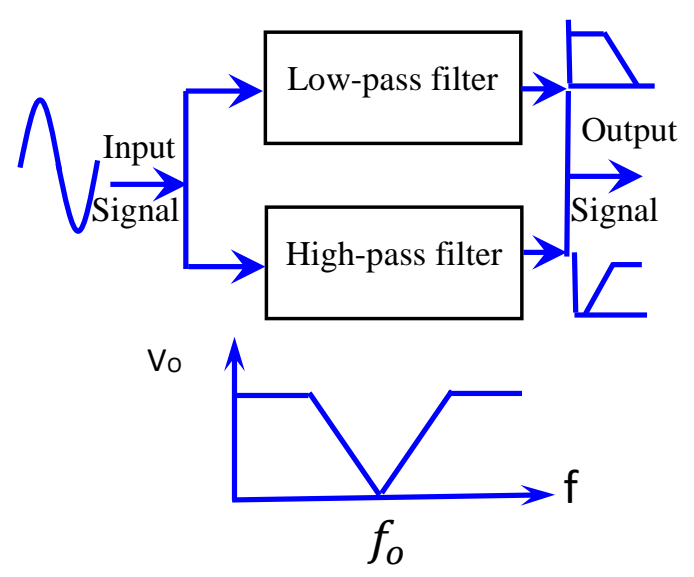

Fig. 1 Band Reject Filter 
The other names of the band-stop filter are the bandelimination, band-reject, or notch filters. Like the band-pass design, we connect the two filter sections (LP and HP) in parallel with each other instead of them in series.

The twin-T network is a handy circuit for the selection of a particular frequency very precisely. One of the parallel twin-T passes the signals without any attenuation, whereas the other does not function in this frequency range. The other parallel twin-T takes over just after the frequency range; the first twin-T network passed the output signal.

This way, for a very narrow range of frequency, neither the first twin-T nor the second twin-T network function, and the signal at the twin-T output gets drastically attenuated. For this reason, its name is a notch filter because it rejects only a notch of frequency.

Notch filters are highly selective because it is a high-Q form of the bandstop filter that can reject a single or very-small band of frequencies rather than a whole bandwidth of frequency. For instance, it may be necessary to reject or attenuate a specific frequency drastically generating electrical noise (such as mains hum) which comes from the inductive load as that of a motor or ballast used in tube light ballast of lighting Circuit, or the removal of harmonics etc.

The musicians in sound equipment such as graphic equalizers, synthesizers, and electronic crossovers use a variable type of notch filter to deal with narrow peaks in the systems' acoustic response. So, we see that notch filters behave in much the same way as low-pass and high-pass filters.

\section{METHOD}

Figure 2 shows a general circuit of a twin-T network [1]-[8]. The low-pass filter section comprises of $\mathrm{Y}_{1}=$ $\mathrm{Y}_{2}=\mathrm{R}$, and $\mathrm{Y}_{6}=\mathrm{sC}_{1}$ in a twin- $\mathrm{T}$ configuration. Similarly, the other parallel filter is the high-pass section comprising of $\mathrm{Y}_{3}=\mathrm{Y}_{4}=\mathrm{C}$ and $\mathrm{Y}_{5}=\mathrm{R}_{1}$ in the complementary- $\mathrm{T}$ configuration. The combined arrangement forms a twin- $\mathrm{T}$ filter, giving a sharp response to the following ratios' component values. The component values for the Twin-T band-stop (an extremely small range of frequency) filter are;

$$
\begin{aligned}
& \mathrm{G}_{1}=2 \mathrm{G} \\
& \mathrm{C}_{1}=2 \mathrm{C}
\end{aligned}
$$

We assume that gs $=\mathrm{YL}=0$, i.e., source and load impedances are very high for further analysis.

A notch filter design has a very narrow and very deep stop band around its center frequency. Its selectivity factor Q describes the notch's width precisely the same way the RLC circuit peaks at one frequency.

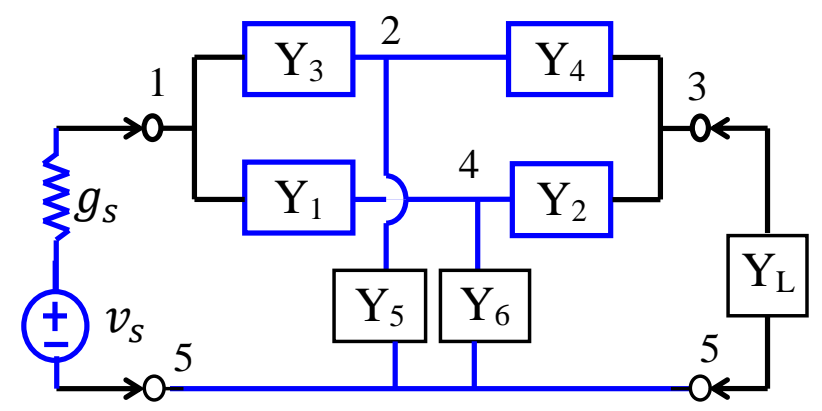

Fig. 2 Twin -T Network

The most common name of the notch filter design is the twin-T-notch filter. In its basic form, the twin- $\mathrm{T}$, is the parallel-tee consists of two RC branches of two tee sections. Each T-section uses either two resistors and a capacitor or two capacitors and one resistor, as in Fig. 2. We are analyzing the twin-T network shown in Fig. 2 to select the particular frequency using the floating admittance matrix approach. For the generalized analysis, we put all capacitors or all resistors in the form of admittances such as $\mathrm{Y}_{1}, \mathrm{Y}_{2}, \mathrm{Y}_{3}, \mathrm{Y}_{4}, \mathrm{Y}_{5}$ and $\mathrm{Y}_{6}$.

The floating admittance matrix of Fig. 2 results [9][15] as;

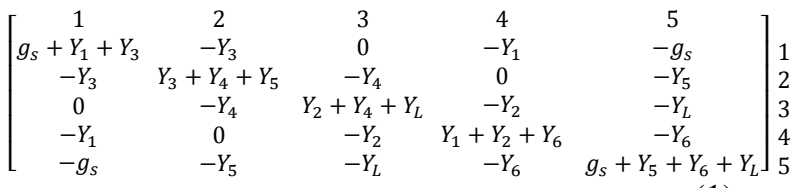

Substituting $\mathrm{Y}_{1}=\mathrm{Y}_{2}=\mathrm{G}, \mathrm{Y}_{3}=\mathrm{Y}_{4}=\mathrm{sC}, \mathrm{Y}_{5}=\mathrm{G}_{1}=$ $2 \mathrm{G}, \mathrm{Y}_{6}=\mathrm{sC}_{1}=2 \mathrm{sC}, \mathrm{g}_{\mathrm{s}}=\mathrm{Y}_{\mathrm{L}}=0$, then Eq. (1) yields;

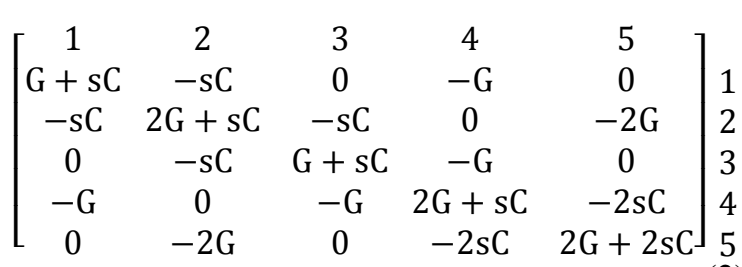

The voltage transfer function between its terminals 3 $\& 5$ and $1 \& 5$ in Fig. 2 can be written [9]-[15] as;

$$
\begin{aligned}
& \left.A_{v}\right|_{15} ^{35}=\operatorname{sgn}(3-5) \operatorname{sgn}(1-5)(-1)^{14} \frac{\left|Y_{35}^{15}\right|}{\left|Y_{15}^{15}\right|} \\
& \left|Y_{35}^{15}\right|=\left|\begin{array}{ccc}
-s C & 2 G+2 s C & 0 \\
0 & -s C & -G \\
-G & 0 & 2 G+2 s C
\end{array}\right| \\
& =\left(s^{2} C^{2}+G^{2}\right) 2(G+s C) \\
& \left|Y_{15}^{15}\right|=\left|\begin{array}{ccc}
2 G+2 s C & -s C & 0 \\
-s C & G+s C & -G \\
0 & -G & 2 G+2 s C
\end{array}\right|
\end{aligned}
$$


$=\left|\begin{array}{ccc}2 G+2 s C & -s C & 0 \\ 2 G+s C & 0 & G+2 s C \\ 0 & -G & 2 G+2 s C\end{array}\right|$

$=2(G+s C)\left\{s^{2} C^{2}+4 s C G+G^{2}\right\}$

$\left.A_{v}\right|_{15} ^{25}=-\frac{2(G+s C)\left(s^{2} C^{2}+G^{2}\right)}{2(G+s C)\left\{s^{2} C^{2}+4 s C G+G^{2}\right\}}$

$=-\frac{\left(1+s^{2} C^{2} R^{2}\right)}{s^{2} C^{2} R^{2}+4 s C R+1}=-\frac{\left(s^{2}+\frac{1}{C^{2} R^{2}}\right)}{s^{2}+s \frac{4}{C R}+\frac{1}{C^{2} R^{2}}}$

$=-\frac{\left(s^{2}+\frac{1}{C^{2} R^{2}}\right)}{s^{2}+s \frac{\omega_{O}}{Q}+\frac{1}{C^{2} R^{2}}}=-\frac{\left(s^{2}+\frac{1}{C^{2} R^{2}}\right)}{s^{2}+s \Delta \omega+\frac{1}{C^{2} R^{2}}}$

$=-\frac{\left(1-\omega^{2} C^{2} R^{2}\right)}{1-\omega^{2} C^{2} R^{2}+j 4 \omega C R+1}=-\frac{1-\frac{\omega^{2}}{\omega_{0}^{2}}}{1-\frac{\omega^{2}}{\omega_{0}^{2}}+j 4 \frac{\omega}{\omega_{0}}}$

where the passive notch filter has notch frequency $=$ $\omega_{0}=\frac{1}{R C}$, bandwidth $=\Delta \omega=\frac{\omega_{O}}{Q}$ and the quality factor $Q_{\text {passive }}=\frac{1}{4}=0.25$. For the fixed value of $\mathrm{R}$ and $\mathrm{C}$, the output voltage is a function of the input voltage frequency.

The absolute value of the transmission coefficient is given as;

$$
\left|A_{v}\right|_{15}^{25} \mid=H_{\text {passive }}(j \omega)=\frac{1-\frac{\omega^{2}}{\omega_{0}^{2}}}{\sqrt{\left(1-\frac{\omega^{2}}{\omega_{0}^{2}}\right)^{2}+\left(4 \frac{\omega}{\omega_{0}}\right)^{2}}}
$$

Fig. 3 shows the dependence of the output voltage or $\left|A_{v}\right|_{15}^{25} \mid=H_{\text {passive }}(j \omega)$ on frequency.

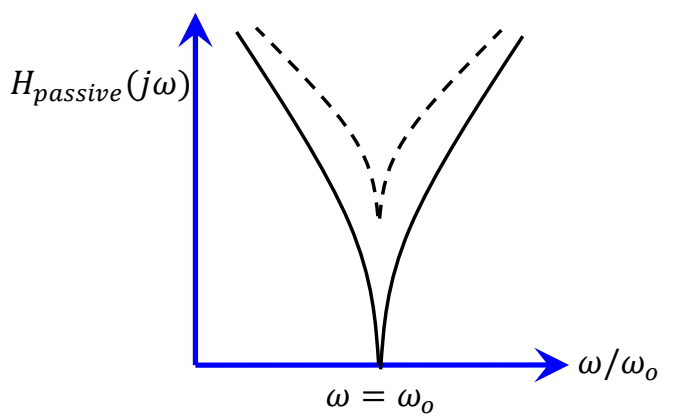

Fig. 3 Plot of absolute value voltage ratio versus frequency

The plot reveals that the voltage ratio $\left|A_{v}\right|_{15}^{25} \mid=$ $H_{\text {passive }}(j \omega)$ ceases to zero at only one frequency i.e.

$$
f_{0}=\frac{1}{2 \pi R C}
$$

The circuit of Fig. 1 functions as a resonant network in the vicinity of this frequency $f_{0}$. This type of circuit is especially suitable at low frequency where the LCR equivalent requires a very large value of $\mathrm{L}$ and C. Figure 4 is the practical circuit for such a conceived network.

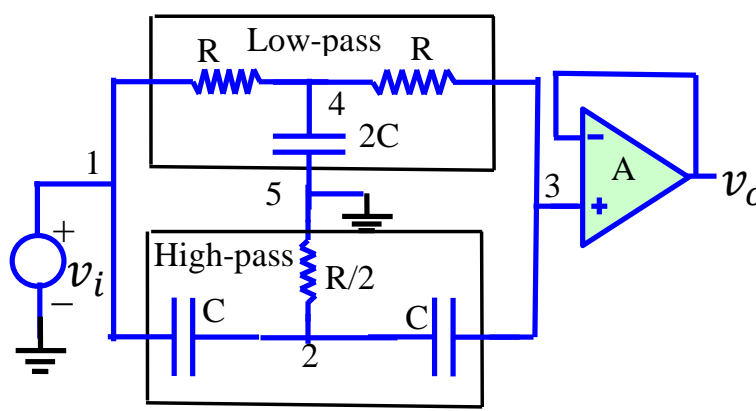

Fig. 4 Twin-T Network with inverting Amplifier

One of the shortcomings of this basic twin-T notch filter design is that the maximum value of the output voltage $\left(v_{35}\right)$ below the notch frequency is normally less than the maximum value of the output voltage w.r.t. that of the output voltage above the notch frequency. This is mainly due to two series resistances (2R) in the low-pass filter section providing higher losses than those of the two series capacitors (C) reactances in the high-pass T-section.

Along with the uneven gains on two sides of the notch frequency, another shortcoming of this basic design is that it has a very low and fixed $Q$ value of 0.25 , of the order of $-12 \mathrm{~dB}$. The current flow through each series of LP section is $180^{\circ}$ apart from the current flow in the each series arm of the HP section of the twin-T network at the notch frequency. This is because of the currents flowing in each series arm, one being $2 \mathrm{R}$ and $2 \mathrm{C}$, are $180^{\circ}$ out of phase, at the notch frequency.

The positive feedback may improve the notch filter by making it more selective. Instead of connecting the junction of $\mathrm{R} / 2$ and $2 \mathrm{C}$ to the ground, i.e. $0 \mathrm{~V}$, it may connect it to a variable point of the voltage divider network fed from the output voltage as in Fig. 5. The voltage divider network decides the amount of feedback that determines the value of $\mathrm{Q}$, which in turn decides the extent of the depth of the notch.

Very frequently, the problem arises in the response of the twin- $T$ circuits due to the lack of precision of passive components used in the network. Also, the quality factor of the circuit is very low as it uses only passive components. It has been observed that the circuit response increases drastically using active circuits of the twin-T network.

Hence, we give a relook for selecting precise values of resistances and capacitances used in the twin- $\mathrm{T}$ filter.

The common terminal in Fig. 5 is not grounded. Instead, it is connected to a potentiometer that functions as a voltage divider composed of $R_{3}$ and $R_{4}$ to form a positive feedback loop. The fraction of the output voltage $v_{o}$ fed back is given as; 


$$
v_{5}=\beta v_{o}=\frac{R_{4}}{R_{3}+R_{4}} v_{o}
$$

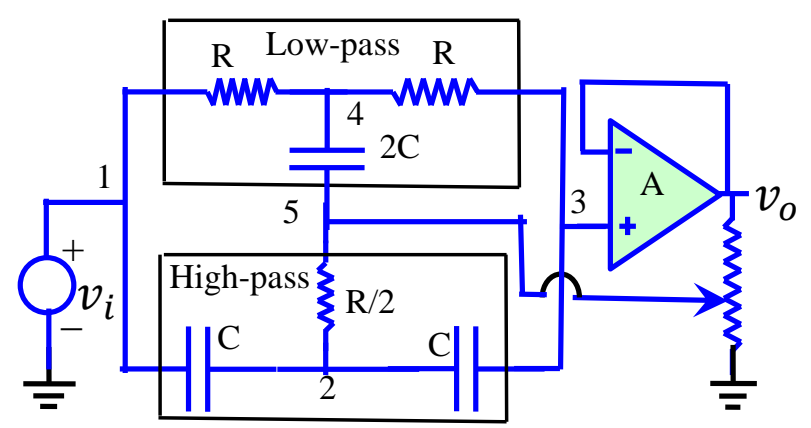

Fig. 5 Twin-T Network with positive feedback

The input voltage $v_{i}-v_{5}$ and the output voltage $v_{o}-v_{5}$ are related by the frequency transfer function $H(j \omega)$ of the twin-T network as;

$$
\begin{gathered}
H(j \omega)=\frac{v_{o}-v_{5}}{v_{i}-v_{5}} \\
\begin{aligned}
& v_{o}-v_{5}=H(j \omega)\left(v_{i}-v_{5}\right) \\
&= H(j \omega) v_{i}-H(j \omega) v_{5} \\
& H(j \omega) v_{i}=v_{o}+\{H(j \omega)-1\} v_{5} \\
&=v_{o}+\{H(j \omega)-1\} \frac{R_{4}}{R_{3}+R_{4}} v_{o} \\
& H(j \omega) v_{i}=\frac{R_{3}+H(j \omega) R_{4}}{R_{3}+R_{4}} v_{o} \\
& \text { Now, } H_{\text {active }}(j \omega)=\frac{v_{0}}{v_{i}}=\frac{H(j \omega)\left(R_{3}+R_{4}\right)}{R_{3}+H(j \omega) R_{4}}
\end{aligned}
\end{gathered}
$$

Now, substituting $H(j \omega)$ from Eq (5) in Eq.(13) results; $\frac{s^{2}+\frac{1}{R^{2} C^{2}}}{s^{2}+\frac{1}{R^{2} C^{2}}+j s\left(\frac{4}{R C}\right)}$

$$
\begin{aligned}
& H_{\text {active }}(j \omega)=\frac{v_{O}}{v_{i}}=\frac{H(j \omega)\left(R_{3}+R_{4}\right)}{R_{3}+H(j \omega) R_{4}} \\
& =\frac{\left(R_{3}+R_{4}\right)\left(s^{2}+\frac{1}{R^{2} C^{2}}\right) /\left(s^{2}+\frac{1}{R^{2} C^{2}}+j s\left(\frac{4}{R C}\right)\right)}{R_{3}+R_{4}\left\{\left(s^{2}+\frac{1}{R^{2} C^{2}}\right) /\left(s^{2}+\frac{1}{R^{2} C^{2}}+j s\left(\frac{4}{R C}\right)\right)\right\}} \\
& =\frac{\left(R_{3}+R_{4}\right)\left(s^{2}+\frac{1}{R^{2} C^{2}}\right)}{R_{3}\left(s^{2}+\frac{1}{R^{2} C^{2}}+s\left(\frac{4}{R C}\right)\right)+R_{4}\left(s^{2}+\frac{1}{R^{2} C^{2}}\right)} \\
& =\frac{\left(R_{3}+R_{4}\right)\left(s^{2}+\frac{1}{R^{2} C^{2}}\right)}{\left(R_{3}+R_{4}\right)\left(s^{2}+\frac{1}{R^{2} C^{2}}\right)+s\left(\frac{4}{R C}\right) R_{3}} \\
& =\frac{\left(s^{2}+\frac{1}{R^{2} C^{2}}\right)}{\left(s^{2}+\frac{1}{R^{2} C^{2}}\right)+s\left(\frac{4}{R C}\right) \frac{R_{3}}{R_{3}+R_{4}}}=\frac{\left(s^{2}+\frac{1}{R^{2} C^{2}}\right)}{\left(s^{2}+\frac{1}{R^{2} C^{2}}\right)+s \frac{\omega_{O}}{Q_{\text {active }}}} \\
& =\frac{\left(s^{2}+\frac{1}{R^{2} C^{2}}\right)}{\left(s^{2}+\frac{1}{R^{2} C^{2}}\right)+s \Delta \omega_{\text {active }}}
\end{aligned}
$$

$$
=\frac{s^{2}+\frac{1}{R^{2} C^{2}}}{s^{2}+\frac{1}{R^{2} C^{2}}+j s\left(\frac{4}{R C}\right)\left(\frac{R_{3}}{R_{3}+R_{4}}\right)}
$$

where the quality factor and the bandwidth of the active filter with positive feedback are given as;

$$
Q_{\text {active }}=\frac{R_{3}+R_{4}}{4 R_{3}}=Q_{\text {passive }}\left(\frac{R_{3}+R_{4}}{R_{3}}\right) \text {, }
$$

And

$$
\Delta \omega_{\text {active }}=\frac{\omega_{o}}{Q_{\text {active }}}
$$

This Eq. (16) suggests that we can adjust the quality factor and the bandwidth of the filter by changing the value of $R_{3}$ and $R_{4}$.

\section{EXPERIMENTAL VERIFICATION}

Three circuits of Figs. 6 and 9 have been designed for practical verifications of the responses. Fig. 9 included an additional inverter in the feedback loop, and its responses are plotted as in Figs.10 and 11.

The outcome of the second type of twin-T filter in Fig. 10 gives the notch frequency and the notch depth inside the block of the plot. Fig. 11 shows the $3 \mathrm{~dB}$ frequencies of the second type of twin-T filter using two Op. Amp inverters.

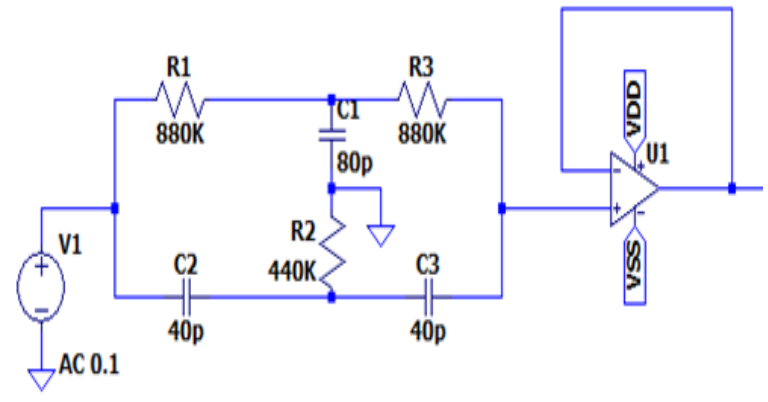

.ac dec 10 1Hz 1 Meg

Fig. 6 Twin-T network

The response of Fig. 6 is given in Figs. 7 and 8. The outcome of notch depth and notch frequency from the plot is inside the block of the plot.

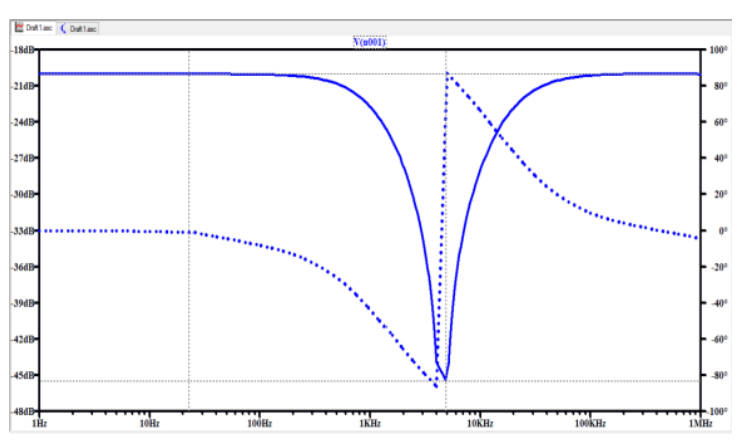




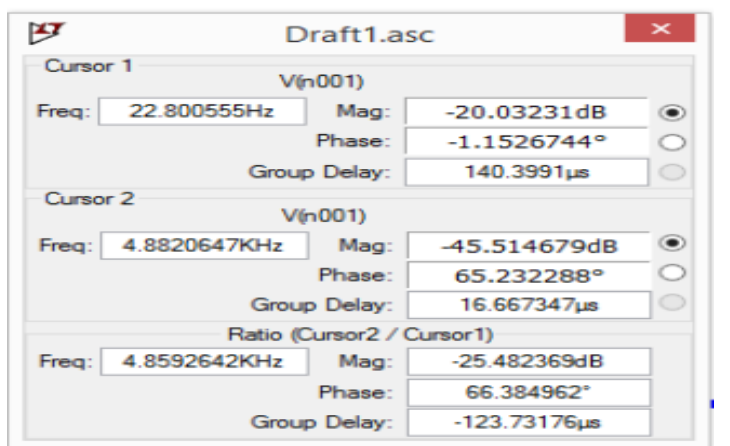

Fig. 7 Indicates notch depth and notch frequency without feedback in the box of the plot
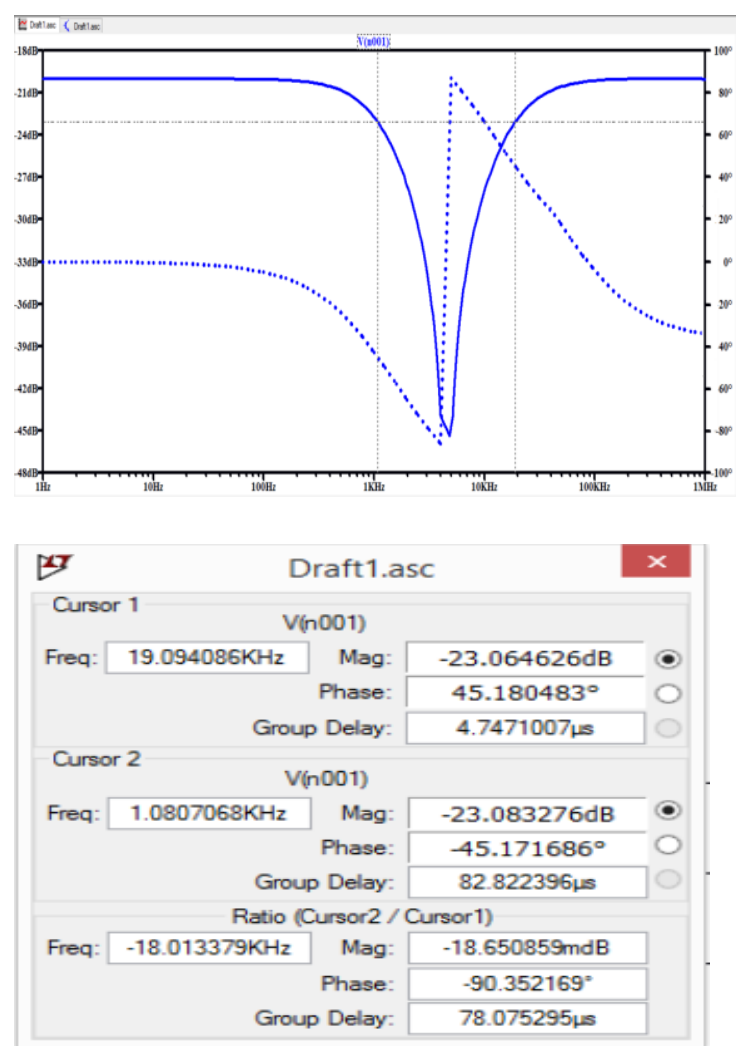

Fig. 8 Indicates $3 \mathrm{~dB}$ frequencies without feedback in the box of the plot

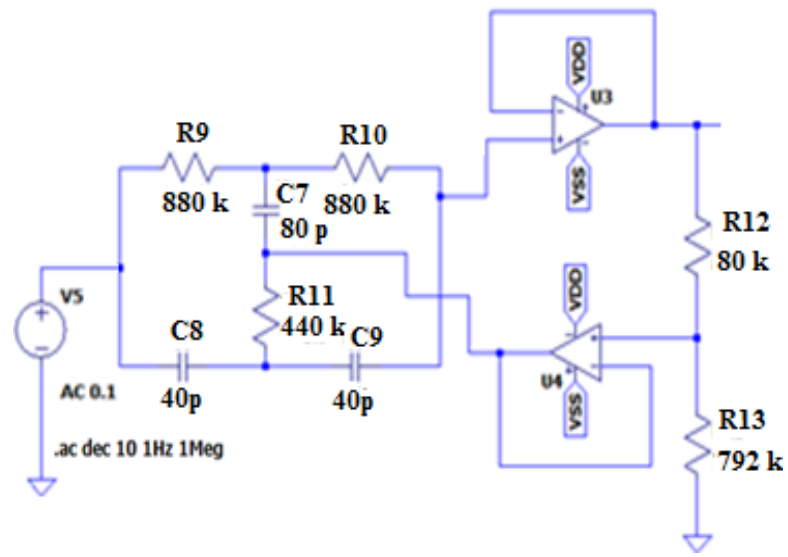

Fig. 10 Twin-T with isolated feedback using an additional inverter in the feedback loop
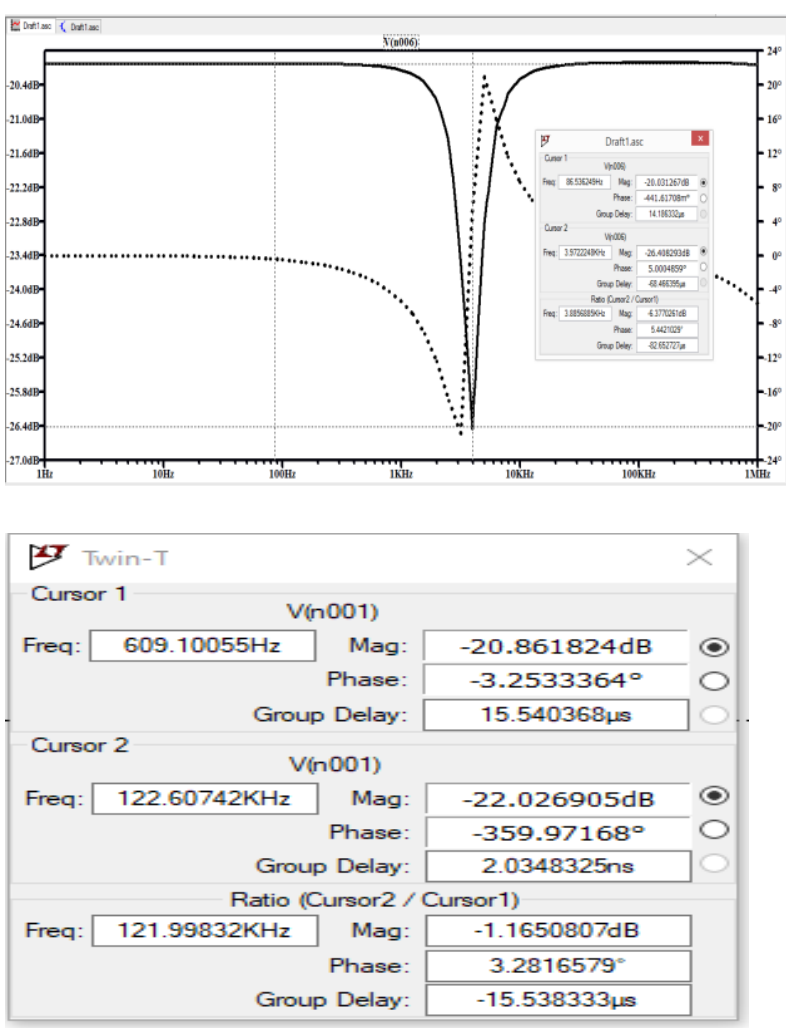

Fig. 10 Indicates notch frequency and notch depth using one Op Amp feedback in the box of the plot

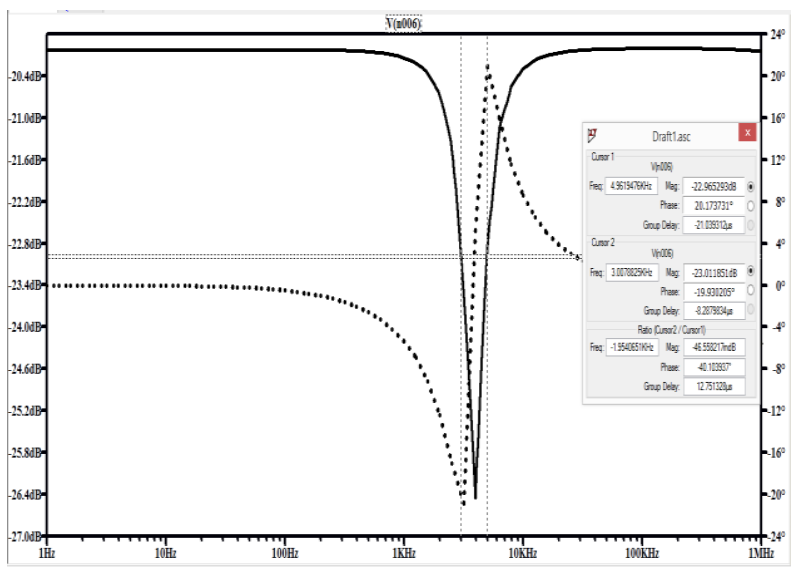

Fig. 11 Indicates $3 \mathrm{~dB}$ frequencies using two Op-Amp feedback in the box of the plot

\section{RESULT AND DISCUSSIONS}

The plots of a twin-T network of Figs. 6 and 9 reveals a close corroboration of the theoretical results. Resistances and capacitances also play important roles in producing very closely related output functions. For that, the precise value of resistances and capacitances must be considered.

Generally, the resistors are available with tolerances of $( \pm 1 \%, \pm 2 \%, \pm 5 \%)$ and adequate in less critical circuits. But, for the twin-T notch filter, tolerances less than these values may be required. Carbon track resistor may be suitable if its measured values on Wayne-Kerr Bridge is taken. The other suitable resistor for such a circuit could be the Cermet 
track variable resistor that gives better reliability. However, a bridge for the exact value of the resistor could be used.

The Silver Mica capacitors have tolerances of $\pm 1 \%$, but the maximum value available is limited to only $4.7 \mathrm{nF}$. They have good temperature stability. Hence, such capacitors are suitable where the filter has to operate in an environment of wide temperature arrange of variation. The Polystyrene capacitors are most suitable for fitters on account of their close tolerances and are available in a large capacitance range. They also have excellent temperature stability. From three forms of ceramic capacitance, metallized, resin dipped, and disc types, the metallized ceramic capacitor has good tolerance $( \pm 2 \%)$ and temperature stability. The polyester type may be of choice for large capacitor values, but their tolerances fall between $(5 \%$ to $(10 \%)$ and their temperature stability is also very poor.

\section{REFERENCES}

[1]. W. L. Everitt and GE Anner, "Communication Engineering", McGraw-Hill, 1937

[2]. Koutsarov, St., Practical circuits of electronic filters. Sofia, Technika Publishing house, 1984.

[3]. Koutsarov, St., Non-inductive electronic filters. Sofia Technika Publishing house, 1977.

[4]. G. S. Moschytz, Linear integrated networks: design, New York (Bell Labs Series): Van Nostrand Reinhold Co., 1975.

[5]. G. S. Moschytz and P. Horn, Active Filter Design Handbook, Chichester, U.K.: Wiley 1981.

[6]. R. P. Sallen and E. L. Key, "A practical Method of Designing $R C$ Active Filters," IRE Trans. on Circ.Th.,vol.CT-2, pp.78-85, 1955.

[7]. Dražen Jurišić* and Neven Mijat, Low-Sensitivity, Low-Noise, Band-Rejection and All-Pass ActiveRC Filters, IEEE ISTE, June 20-23, 200, Dubrovnik Croatia.

[8]. M. Bogdan, M. Panu: "Lab View Modeling and simulation of the Low pass and High Pass analog filters". 2015 13th International Conference on Engineering of Modern Electric Systems (EMES)

[9]. DBSJ Prasada Rao and B. P. Singh," A unified to Electronic Circuit Analysis using Indefinite Admittance Matrix, Int. J. Elect. Enging Educ., Vol. 15, pp. 267-275, 1978.

[10]. B. P. SINGH, "On demand realization of a frequency-dependent negative resistance and an infinite input impedance" International Journal of Electronics Theoretical and Experimental, Taylor \& Francis, Vol.44, no. 3 (1978): 243-249.

[11]. M. Singh, S. K. Roy, and B. P. Singh, "On Demand Realization of Input and Output Resistances of MOSFET Amplifier". In American Institute of Physics Conference Proceedings, vol. 1414, no. 1, pp. 266-270. AIP, 2011.

[12]. B. P. Singh, "Minimum Sensitive FET Filter", Indian J. Pure \& Appl. Phys. (India), Vol.20. pp. 389, May 1982, ISSN: 0019-5596.

[13]. M.Singh and P. Prerna, "Floating Admittance Matrix Modeling Approach to BJT," IJRSI, Vol. VI, Issue X, October 2019.

[14]. S. K. Roy, M. Singh, K. K. Sharma, B. Cherry, and B. P. Singh, "Mathematical Modelling of
Semiconductor Devices and circuits: A Review;" $3^{\text {rd }}$ International Conference on Intelligent Circuits and Systems (ICICS), June 26-27, 2020, Lovely Professional University, (Phagwara) Punjab.

[15]. S. K. Roy, M. Singh, K. K. Sharma, B. Cherry, and B. P. Singh, "Mathematical Modelling of Simple Passive RC Filters Using Floating Admittance Technique," 2020 IEEE International Conference for Innovation in Technology (INOCON-20), Bengaluru, India. Nov 6-8, 2020.

\section{Creative Commons Attribution License 4.0 (Attribution 4.0 International, CC BY 4.0)}

This article is published under the terms of the Creative Commons Attribution License 4.0 https://creativecommons.org/licenses/by/4.0/deed.en_US 